\title{
Opinion
}

\section{People with epilepsy receiving renal replacement therapy with hemodialysis Scientists recall progress and promise of translational research}

\author{
Fulvio A. Scorza ${ }^{1}$, Ricardo M. Arida ${ }^{2}$, Vera C. Terra ${ }^{3}$, Rui Alberto Gomes ${ }^{4}$, Esper A. Cavalheiro'
}

Nowadays, we have observed that discoveries in medical sciences have rapidly accelerated and continue to expand. One of the reasons for these positive recent changes is due to the onset of translational research. The term translational research, which was recently incorporated in the dictionary of medical sciences, indicates the integration of the advancements in basic science with clinical trials, taking research from the "bench-to-bedside" ${ }^{1}$. This perspective gives rise to a completely new approach to improving health care for people with chronic diseases. Following this line of thought, we currently know that this scientific convergence works very well in several fields ${ }^{1}$, but can still be considered rare among nephrologists and neurologists. Evaluating the field of nephrology, the chronic renal failure, a progressive loss of kidney function that results in permanent kidney failure, is a worldwide public health problem. Furthermore, individuals in this condition need dialysis or a transplanted kidney. Even more problematic than these aspects, renal failure is associated with an increased risk of cardiovascular disease and sudden death ${ }^{2}$. Now, looking through the prism of Neurology, we know that epilepsy is considered the most common serious neurological condition. Unfortunately, each year about one in a 1000 patients with chronic epilepsy will die suddenly, unexpectedly, and without explanation, even with post-mortem examination ${ }^{3}$. Among neurologists around the world, this phenomenon is called sudden unexplained death in epilepsy (SUDEP). In the actual scenario, epilepsy is associated with a two- to three-fold increase in mortality compared to the general population, and SUDEP is the most important direct epilepsy-related cause of death ${ }^{3}$. Thus, as these two chronic diseases are very common in the world and also a global public health problem, a new line of translational research would have great value in helping neurologists and nephrologists to investigate what would be the best strategy to be drawn if these two chronic diseases involve the same individual. From this perspective and mainly due lack of data in the world, our research group decided to investigate the possible relationship between seizure frequencies in patients with end-stage renal disease (ESRD) under regular dialysis program ${ }^{4}$. Briefly, from 189 ESRD patients, 7 had suffered some type of convulsive seizure during dialytic program ${ }^{4}$. At that time, we concluded that despite the occurrence of seizures is considered rare among ESRD individuals receiving dialysis, it should be apparent that a true convergence of clinical nephrology and neurology should always be part of this scenario ${ }^{4}$. The next step for the researchers of our Institute of Nephrology was to verify the possible association between epilepsy and hence SUDEP in these individuals ${ }^{5}$. Overall, we noted in all the cases evaluated (7 out of 209) that cardiovascular abnormalities and hence SUDEP is a rare event in ESRD people with epilepsy receiving dialy$\mathrm{sis}^{5}$. Although these data have to be interpreted with caution due to a small number of cases examined, we continue to believe that the flame of translational science among professionals directly involved with these patients must be permanently lit.

In sum, it has been repeatedly and firmly established in medical literature that chronic diseases, epilepsy and chronic renal insufficiency in this particular case, have extraordinarily high mortality rates and dialysis people and individuals with epilepsy are at increased risk of sudden

\section{PACIENTES COM EPILEPSIA RECEBENDO TERAPIA DE REPOSIÇÃO COM HEMODIÁLISE: CIENTISTAS RECORDAM O PROGRESSO E AS PROMESSAS DAS PESQUISAS TRANSLACIONAIS}

${ }^{1}$ Disciplina de Neurologia Experimental. Universidade Federal de São Paulo/Escola Paulista de Medicina (UNIFESP/EPM). São Paulo SP, Brazil; ${ }^{2}$ Departamento de Fisiologia. Universidade Federal de São Paulo/Escola Paulista de Medicina (UNIFESP/EPM). São Paulo SP, Brazil; ${ }^{3}$ Centro de Cirurgia de Epilepsia (CIREP). Departamento de Neurociências e Ciências do Comportamento. Faculdade de Medicina de Ribeirão Preto, Universidade de São Paulo. Ribeirão Preto SP, Brazil; ${ }^{4}$ Instituto de Nefrologia de Mogi das Cruzes, Mogi das Cruzes SP, Brazil.

Fulvio Alexandre Scorza - Rua Botucatu 862 - 04023-900 São Paulo SP - Brasil. E-mail: scorza.nexp@epm.br 
cardiac death in general. In this sense, while the translational science developed between nephrologists and neurologists is unable to prevent the installation of these illnesses or even completely reverse the clinical picture when both are already installed, some preventive strategies (already established in the literature for the situations mentioned here $)^{6-9}$ should be part of clinical routine of these professionals and obviously adhered to by patients in order to prevent the occurrence of cardiovascular abnormalities and hence sudden cardiac death: [1] maintain a healthy weight, consume a healthy and balanced diet, avoid smoking, and consume a limited amount of alcohol; [2] maintain a regular practice of physical activity under the supervision of a qualified professional; [3] establish a diet with omega 3 fatty acids from fish or fish oil supplements is strongly recommended; [4] maintain a good quality of sleep; [5] manage stress by changing the way you respond to stress, making time for relaxation, and learning healthier coping strategies.

Finally, trying to solve these considerations is never an easy task; nephrologists and neurologists should really start thinking of a way translational and have to keep in mind that is time to establish a task force to assess the state of knowledge (clinical management, research directions, and educational, social and cultural efforts). As every journey begins with the first step, draws up a list of all the current problems present and evaluates which ones merit fixing and which ones are actually fixable should provide a promising future.

ACKNOWLEDGEMENTS - The authors thank FAPESP, CInAPCeFAPESP, INCT/MCT and CNPq for supporting our studies.

\section{REFERENCES}

1. Goldblatt EM, Lee WH. From bench to bedside: the growing use of translational research in cancer medicine. Am J Transl Res 2010;2:1-18.

2. Herzog CA, Mangrum JM, Passman R. Sudden cardiac death and dialysis patients. Semin Dial 2008;21:300-307.

3. Surges R, Thijs RD, Tan HL, Sander JW. Sudden unexpected death in epilepsy: risk factors and potential pathomechanisms. Nat Rev Neurol 2009; 5:492-504.

4. Scorza FA, Albuquerque M, Arida RM, et al. Seizure occurrence in patients with chronic renal insufficiency in regular hemodialysis program. Arq Neuropsiquiatr 2005;63:757-760.

5. Gomes RA, Kesrouani S, Cruz J, et al. Is there something special about cardiovascular abnormalities and sudden unexpected death in epilepsy among patients with chronic renal insufficiency in regular hemodialysis program? Arq Neuropsiquiatr 2009;67:209-213.

6. Scorza FA, Arida RM, Terra VC, Cavalheiro EA. What can be done to reduce the risk of SUDEP? Epilepsy Behav 2010;18:137-138.

7. Bennett $P N$, Breugelmans $L$, Barnard $R$, et al. Sustaining a hemodialysis exercise program: a review. Semin Dial 2010; 23:62-73.

8. Scorza FA, Cysneiros RM, Arida RM, Terra-Bustamante VC, de Albuquerque $M$, Cavalheiro EA. The other side of the coin: beneficiary effect of omega-3 fatty acids in sudden unexpected death in epilepsy. Epilepsy Behav 2008;13:279-283.

9. Friedman $\mathrm{A}$, Moe $\mathrm{S}$. Review of the effects of omega-3 supplementation in dialysis patients. Clin J Am Soc Nephrol 2006;1:182-192. 